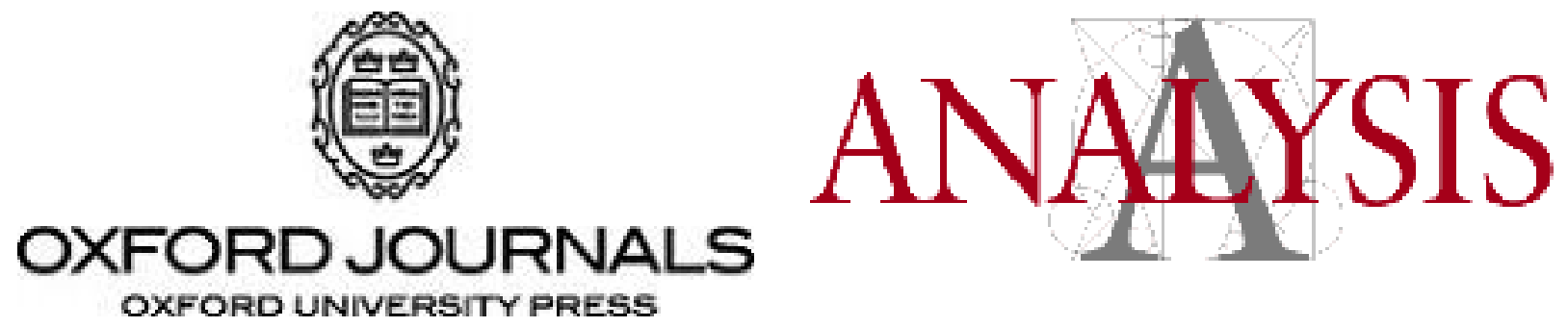

In Defence of the Letter of Fictionalism

Author(s): Harold W. Noonan

Source: Analysis, Vol. 54, No. 3 (Jul., 1994), pp. 133-139

Published by: Oxford University Press on behalf of The Analysis Committee

Stable URL: http://www.jstor.org/stable/3328661

Accessed: 24/01/2011 13:01

Your use of the JSTOR archive indicates your acceptance of JSTOR's Terms and Conditions of Use, available at http://www.jstor.org/page/info/about/policies/terms.jsp. JSTOR's Terms and Conditions of Use provides, in part, that unless you have obtained prior permission, you may not download an entire issue of a journal or multiple copies of articles, and you may use content in the JSTOR archive only for your personal, non-commercial use.

Please contact the publisher regarding any further use of this work. Publisher contact information may be obtained at http://www.jstor.org/action/showPublisher?publisherCode=oup.

Each copy of any part of a JSTOR transmission must contain the same copyright notice that appears on the screen or printed page of such transmission.

JSTOR is a not-for-profit service that helps scholars, researchers, and students discover, use, and build upon a wide range of content in a trusted digital archive. We use information technology and tools to increase productivity and facilitate new forms of scholarship. For more information about JSTOR, please contact support@jstor.org.

Oxford University Press and The Analysis Committee are collaborating with JSTOR to digitize, preserve and extend access to Analysis. 


\title{
In Defence of the Letter of Fictionalism
}

\author{
HaRold W. NoONAN
}

1. In his article [5] Gideon Rosen puts forward an account of modal discourse which suggests how one can translate such discourse into possible world discourse without any untoward ontological commitments. As David Lewis has amply demonstrated, translation of modal discourse into possible world discourse has many advantages, but the problem is to see how to obtain these advantages without attracting the 'incredulous stare', or more bluntly, without being regarded as a raving lunatic. Rosen suggests how. Specifically his suggestion is the following. Let $\mathrm{P}$ be any modal sentence and $\mathrm{P}_{\mathrm{L}}$ its translation into Lewisean counterpart theory. Then, Rosen suggests, the correct translation of $\mathrm{P}$ into possible world discourse is not $\mathrm{P}_{\mathrm{L}}$ but rather 'According to the Lewisean hypothesis of a plurality of worlds, $\mathrm{P}_{\mathrm{L}}$ ', that is, 'According to the fiction that there is a plurality of worlds, $\mathrm{P}_{\mathrm{L}}$.

Thus, according to Rosen [5], the modal fictionalist (as he entitles the proponent of this position) should endorse the following translation schema for modal propositions (where '(PW)' abbreviates 'the Lewisean hypothesis of a plurality of worlds'):

(1) $\mathrm{P}$ if and only if according to (PW), $\mathrm{P}_{\mathrm{L}}$.

However, Rosen [6] brings forward an objection to this proposal (also brought forward by Brock [1]). In [4] Peter Menzies and Philip Pettit endorse this objection, but suggest that it is decisive only against the letter of the Rosen proposal in [5], i.e. the 'simple prefixing strategy' encapsulated in schema (1). The spirit of modal fictionalism can, however, be retained, they suggest, by suitable modification of (1).

The aim of this paper is to show that Menzies and Pettit are being unnecessarily concessive. The objection of Rosen [6] and Brock [1] is unsound, and so the letter and not just the spirit of Rosen's original modal fictionalism can be retained - at least, that is, it can be retained unless there are any other objections to it.

2. The Rosen-Brock objection goes as follows. We know that the following is true (taking the modalities to be logical modalities that conform to the modal logic S5):

(2) Necessarily, it is contingent that kangaroos exist.

Since this is true the fictionalist had better accept it. 
But the translation of this into Lewisean counterpart theory is:

(3) For all worlds $w$, at $w$ there is a world $w^{\prime}$ at which kangaroos exist and a world $w^{\prime \prime}$ at which kangaroos do not exist.

Hence the correct translation of (2) into possible world discourse according to the fictionalist schema (1) is:

(3P) According to (PW), for all worlds $w$, at $w$ there is a world $w^{\prime}$ at which kangaroos exist and a world $w^{\prime \prime}$ at which kangaroos do not exist.

But (3) implies:

(4) For all worlds $w$, at $w$ there are several (at least two) worlds.

Hence (3P) implies:

(4P) According to (PW), for all worlds $w$, at $w$ there are several worlds.

But (4) is the Lewisean translation of:

(6) Necessarily, there are several worlds.

Hence, according to schema (1), (4P) is the correct translation of (6). Thus the fictionalist, since he accepts (2), must accept (6), since (2) is, according to him, equivalent to (3P), which entails $(4 \mathrm{P})$ which is equivalent, according to him, to (6). But (6) entails:

(7) There are several worlds,

to which it was precisely the point of the fictionalist proposal to avoid commitment.

3. Menzies and Pettit think that this objection is decisive against the letter of the Rosen proposal encapsulated in (1). However, they are wrong. For what the objection crucially assumes is that the translation of (2) into Lewisean counterpart theory entails the translation of (6) into Lewisean counterpart theory (that is, that what Menzies and Pettit write as (3) entails what they write as (4)). But this is incorrect.

According to Lewis [2] translation into counterpart theory of a sentence of quantified modal logic must proceed by way of the general translation scheme he describes in section II of that paper ('Translation'), or by way of the modification of that scheme he introduces in section $\mathrm{V}$ ('Relative Modalities'). Let us consider these in turn. (In the following translations variables range over possible individuals, including worlds, 'Ixy' denotes the relation between $x$ and $y$ when $x$ is in $y$, 'W $x$ ' means ' $x$ is a world', ' $\mathrm{R}$ ' denotes the characteristic relation for the relative modality in question, and, of course, ' $K x$ ' means ' $x$ is a kangaroo'.) 
According to the proposal in Lewis's section II the translation of (2), $\square(\diamond(\exists x) \mathrm{K} x \& \diamond \neg(\exists x) \mathrm{K} x)$, is:

(3L) $(\forall w)\left(\mathrm{W} w \rightarrow\left(\left(\exists w^{\prime}\right)\left(\mathrm{W} w^{\prime} \&(\exists x)\left(\mathrm{L} x w^{\prime} \& \mathrm{~K} x\right)\right) \&\right.\right.$

$$
\left.\left.\left(\exists w^{\prime \prime}\right)\left(\mathrm{W} w^{\prime \prime} \& \neg(\exists x)\left(\mathrm{I} x w^{\prime \prime} \& \mathrm{~K} x\right)\right)\right)\right) .
$$

The translation of $(6), \square\left(\exists w^{\prime}\right)\left(\exists w^{\prime \prime}\right)\left(\mathrm{W} w^{\prime} \& \mathrm{~W} w^{\prime \prime} \& \neg w^{\prime}=w^{\prime \prime}\right)$, is:

(4L) $(\forall w)\left(\mathrm{W} w \rightarrow\left(\exists w^{\prime}\right)\left(\mathrm{I} w^{\prime} w \& \mathbb{W} w^{\prime} \&\right.\right.$

$$
\left.\left.\left(\exists w^{\prime \prime}\right)\left(\mathrm{I} w^{\prime \prime} w \& \mathrm{~W} w^{\prime \prime} \& \neg w^{\prime}=w^{\prime \prime}\right)\right)\right) .
$$

But, of course, (3L) does not entail $(4 \mathrm{~L})$, nor would Lewis wish to say that it did, since according to (PW), (3L) is true and $(4 \mathrm{~L})$ is false.

According to the alternative translation scheme Lewis gives in his section $\mathrm{V}$, the translation of $(3)$ is:

$\left(3 \mathrm{~L}^{\prime}\right)(\forall w)\left(\mathrm{R} w @ \rightarrow\left(\left(\exists w^{\prime}\right)\left(\mathrm{R} w^{\prime} w \&(\exists x)\left(\mathrm{I} x w^{\prime} \& \mathrm{~K} x\right)\right)\right.\right.$

$$
\left.\left.\&\left(\exists w^{\prime \prime}\right)\left(\mathrm{R} w^{\prime \prime} w \& \neg(\exists x)\left(\mathrm{I} x w^{\prime \prime} \& \mathrm{~K} x\right)\right)\right)\right) .
$$

The translation of $(6)$ is:

$\left(4 \mathrm{~L}^{\prime}\right)(\forall w)\left(\mathrm{R} w @ \rightarrow\left(\exists w^{\prime}\right)\left(\mathrm{I} w^{\prime} w \& \mathrm{~W} w^{\prime} \&\right.\right.$

$$
\left.\left.\left(\exists w^{\prime \prime}\right)\left(\mathrm{I} w^{\prime \prime} w \& \mathrm{~W} w^{\prime \prime} \& \neg w^{\prime}=w^{\prime \prime}\right)\right)\right) .
$$

$\left(3 L^{\prime}\right)$ does not entail $\left(4 L^{\prime}\right)$, and again, according to $(P W),\left(3 L^{\prime}\right)$ is true and $\left(4 L^{\prime}\right)$ is false.

Whichever of the Lewisean transaction schemes we employ, then, the Lewisean translation of (2) does not entail the Lewisean translation of (6). Hence the correct translation of (2), according to schema (1), got by prefixing the Lewisean translation of (2) by 'According to (PW)', does not entail the correct translation of (6) according to schema (1), got by prefixing the Lewisean translation of (6) by 'According to (PW)'. The modal fictionalist thus has no reason to reject schema (1).

4. But where, then, are Rosen, Brock, Menzies and Pettit mistaken? Are they mistaken in thinking that (3) and (4) are correct translations into informal language of the Lewisean counterpart theoretic translations of (2) and (6), or are they mistaken in thinking that (3), even as they write it, entails (4)?

Consider first the situation with respect to Lewis's first translation schema, according to which the translation of $(2)$ is $(3 \mathrm{~L})$ and the translation of $(6)$ is $(4 \mathrm{~L})$ (which is the translation schema Lewis thinks appropriate for the logical modalities).

Comparing (3) with (3L) we see that there is nothing in $(3 \mathrm{~L})$ to correspond to the occurrence of 'at $w$ ' in (3), though the two occurrences of 'at which' in (3) ('at $w$ "' and 'at $w$ "') correspond to the open sentences ' $I x w$ '" and ' $I x w^{\prime \prime}$ ' in $(3 \mathrm{~L})$. Thus, $(3)$ is an incorrect translation of $(3 \mathrm{~L})$. 


\section{I36 HAROLD W. NOONAN}

The correct translation of $(3 \mathrm{~L})$ into informal language is:

(3C) For all worlds $w$, there is a world $w^{\prime}$ at which kangaroos exist and a world $w^{\prime \prime}$ at which kangaroos do not exist,

which follows from, but is weaker than:

(3S) There is a world $w^{\prime}$ at which kangaroos exist and a world $w^{\prime \prime}$ at which kangaroos do not exist.

Comparing (4) with (4L), however, we can see that matters stand differently. Corresponding to 'at $w$ ' in (4) are the two open sentences ' $I$ ' $w$ ' $w$ ' and ' $I w^{\prime \prime} w$ ' in $(4 \mathrm{~L})$. Thus (4) can be read as a correct informal translation of (4L) where 'at $w$ ' is read as 'in $w$ '.

Read in this way, however, (4) is not entailed by (3) since it is not entailed by the stronger (3S): it does not follow from the proposition that there are several worlds with distinct properties that every (or, indeed, any) world has such distinct worlds in it.

Let us now consider Lewis's second translation scheme, according to which the correct translation of $(2)$ into counterpart theory is $\left(3 \mathrm{~L}^{\prime}\right)$ and the correct translation of $(6)$ is $\left(4 \mathrm{~L}^{\prime}\right)$.

Comparing (3) with $\left(3 \mathrm{~L}^{\prime}\right)$ we see that corresponding to the occurrence of 'at $w$ ' in (3) are the two open sentences ' $\mathrm{R} w$ ' $w$ ' and ' $\mathrm{R} w$ ' $w$ ' in (3L'). Hence, the occurrence of 'at $w$ ' here can now be read as 'bears the characteristic relation to $w$ ' or 'accessible from $w$ '. Corresponding to the two occurrences of 'at which' (i.e. 'at $w^{\prime \prime}$ ' and 'at $w^{\prime \prime \prime}$ ') are the open sentences ' $I x w$ ' and ' $I x w$ '". Hence, these occurrences of 'at which' can be read 'in which'. Read in this way (3) can thus be seen as a correct informal translation of $\left(3 \mathrm{~L}^{\prime}\right)$, in which the occurrence of 'at $w$ ' is not redundant.

Comparing (4) with $\left(4 L^{\prime}\right)$ we see that corresponding to the occurrence of 'at $w$ ' in (4) are the two open sentences ' $\mathrm{I} w$ ' $w$ ', and ' $\mathrm{I} w$ ' $w$ ' in (4L'). Thus (4) can be read as a correct informal translation of $\left(4 \mathrm{~L}^{\prime}\right)$ where 'at $w$ ' is read as 'in $w$ ' (and 'for all worlds $w$ ' is read as elliptical for 'for all worlds $w$ accessible from the actual world').

But with (3) and (4) thus understood we see that 'at $w$ ' is ambiguous between 'accessible from $w$ ' in (3) and 'in $w$ ' in (4), and the move from (3) to $(4)$ is vitiated by this ambiguity. ${ }^{1}$

1 Of course, 'at $w$ ' in (4) can be read as 'accessible from $w$ ' (I can read 'the sky is blue' as 'grass is green' if I like). Then (4) follows from (3), but then also (4) is not a translation, by either of the Lewisean accounts, of (6). Thus we see that the mistake lying behind the view that the Brock-Rosen objection refutes schema (1) is the belief that 'Necessarily, there are several worlds' must be translated by the Lewisean translation method into what a modal realist would regard as a truth. In fact, both Lewisean translation schemes translate it into what Lewis holds to be a false proposition. But could not Lewis modify his translation method to make 'Necessarily, there are several 
The ambiguity of 'at $w$ ' in (3) and (4), read as translations of $\left(3 L^{\prime}\right)$ and $(4 \mathrm{~L}$ '), between 'accessible from $w$ ' and 'in $w$ ' is one Menzies and Pettit are aware of, but they do not get it properly into focus (and incidentally, they are unwarranted in supposing that Lewis's use of 'at $w$ ' is ambiguous in this way - in fact, he never uses it in the former sense). They mark the ambiguity by subscripts 'at ${ }_{1} w$ ' (for 'in $w$ ') and 'at ${ }_{2} w$ ' (for 'accessible from $\left.w^{\prime}\right)$, and they appeal to it in their justification of their proposed amendments to the simple prefixing schema (1). But they do not see that this ambiguity is (a) already enough to block the objection to schema (1) if the Lewisean translations appealed to are those given by his translation scheme for relative modalities, and (b) is irrelevant (since it then does not occur in (3) - or (3C) - and (4)) if the Lewisean translations appealed to are those given by his translation scheme for logical modalities (in which case, as we have seen, it is the incorrectness of (3) as a statement of the Lewisean translation of (2) which is the weak link in the Rosen-Brock argument). Moreover, they do not appreciate that, since they take the modalities involved in the objection to be the logical modalities, they themselves ought to regard this ambiguity as irrelevant, that is, they do not appreciate that, ignoring relative modalities, all 'at' contexts are of the $a t_{1}$ kind and consequently, if the simple prefixing proposal is adequate for such contexts (as they say it is), it is adequate for all contexts.

5. In their final section Menzies and Pettit consider a last difficulty, reflection on which will allow us to attend to an objection that the reader will have been wanting to make for some time. The difficulty Menzies and Pettit consider is whether they have left room in their account for the modal fictionalist to assert that possibly (PW) is false, that possibly there is only one world.

On the account I have defended, of course, this is no difficulty. The fictionalist can happily assent to all three of 'There is only one world', 'Possibly, there is only one world' and 'Necessarily, there is only one world', and can justify his assent to the latter two modal sentences by appeal to the prefixing schema (1).

possible worlds' come out true? He could indeed. For example, by stipulating that 'I $x y$ ' is to hold between $x$ and $y$, not only when $x$ is part of $y$ but also when $x$ is accessible from $y$, which in the case of the logical modalities is just when $x$ and $y$ are worlds. If Lewis were so to modify his translation method and the modal fictionalist were then foolishly to endorse schema (1) with the subscripted ' $L$ ' of ' $P_{L}$ ' read as referring to the modified Lewisean translation of $\mathrm{P}$ he would indeed be involved in an inconsistency. But clearly, all the fictionalist need do to ensure the consistency of his account is to insist that the subscripted ' $\mathrm{L}$ ' of ' $\mathrm{P}_{\mathrm{L}}$ ' be read as a reference to Lewis-asof -1968 - not to some hypothetical future Lewis stage which has introduced such a modification. 


\section{38 HAROLD W. NOONAN}

But he can do so, of course, only because Lewis himself is committed to maintaining that these last two sentences are true, and is committed to maintaining to be false 'Necessarily, there are many worlds'. ${ }^{2}$ However, does this not merely indicate that Lewis's translation scheme is inadequate to his modal metaphysics? For must not any modal realist worth his salt be able to assert, not only that there are many possible worlds (as Lewis can, recall footnote 2 ), but that necessarily there are many possible worlds? And if so, does it not follow that the defence of the letter of fictionalism given above depends on an appeal to a modal realist translation scheme Lewisean counterpart theory - which, by the modal realist's own lights, must be regarded as unsatisfactory?

I think not. Lewis can, of course, introduce a modification to his translation scheme which makes 'Necessarily, there are many worlds' true - as noted in footnote 1 he can simply stipulate that ' $I x y$ ' is to be true whenever $x$ is accessible from $y$. But he need not do so, and there is good reason why he should not. For on Lewis's account the function of a modal operator is to combine quantification over possible worlds with restrictions on the domains of the quantifiers lying within the scope of the modal operator. Thus a modal operator conceals a restricting modifier, 'at world $u$ ', which functions in much the same way as the restricting modifier 'In Australia'. 'In Australia, all swans are black' tells us that if we ignore everything not in Australia, if we quantify only over things in Australia, then all swans are black. Similarly, 'Possibly, all swans are blue' tells us that at some strange world $w$, all swans are blue, that is, quantifying only over things that are part of $w$, all swans are blue. Mutatis mutandis, 'Necessarily, all swans are birds' says that for any world $w$, quantifying only over parts of $w$, all swans are birds.

Lewis notes that 'restrictive modifiers need not restrict all quantifiers in their scope, without exception, "In Australia, there is a yacht faster than any other" would mean less than it does if the modifier restricted both quantifiers rather than just the first. "Nowadays there are rulers more dangerous than any ancient Roman" would be trivialised if we ignored those ancient Romans who are not alive nowadays. "At some small world there is a natural number too big to measure any class of individuals" can be true even if the large number that makes it true is no part of the small world' ([3], p. 6). Nevertheless, the function of a restrictive modifier is to restrict the domains of quantifiers within its scope, and hence an expres-

${ }^{2} \mathrm{He}$ is also committed to holding that in one sense, as a sentence of quantified modal logic that contains no modal operator, the first sentence, 'There is only one world', is true, because equivalent to 'As part of the actual world, there is only one world'. But Lewis, of course, can and does acknowledge a second sense in which this is false, when the domain of the quantifier is unrestricted. 
sion is not functioning as a restrictive modifier if it restricts the domain of no quantifier within its scope. Consequently, an expression is not functioning, on Lewis's account, as a modal operator unless it both introduces quantification over possible worlds and restricts the domain of at least one quantifier within its scope.

But now we can see that if Lewis were to understand 'Necessarily, there are many possible worlds' in the way that would be required to make it true, then, by his account of how modal operators function, 'Necessarily' as it occurs in this sentence would not be functioning as a modal operator, since it would not restrict the domain of any quantifier within its scope it would, as it were, be logically inert and 'Necessarily, there are many possible worlds' would say no more nor less than 'There are possible worlds' (just as 'In Australia, all swans are black' would say no more nor less than 'All swans are black' if we were to stipulate that a sufficient condition of something's being 'in' Australia was that it was spatio-temporally related to Australia).

I think then that it is no oversight on Lewis's part that he does not stipulate a sense for 'Necessarily, there are many possible worlds' on which it is true, and that there is no reason to regard the translation schemes in his [2] as inadequate on this score. Consequently then, it is no objection to the fictionalist's prefixing schema (1) that it can only be retained if the subscripted ' $\mathrm{L}$ ' is read as a reference to Lewis-as-of-1968 - for Lewis-as-of1968 should be regarded, from the modal realist's perspective, as giving the correct translation scheme for modal discourse.

University of Birmingham, Birmingham, B15 2TT

\section{References}

[1] Stuart Brock, 'Modal Fictionalism: A reply to Rosen', Mind 102 (1993) 147-50.

[2] David Lewis, 'Counterpart Theory and Quantified Modal Logic', Journal of Philosophy 65 (1968) 113-26.

[3] David Lewis, On the Plurality of Worlds (Oxford: Blackwell, 1986).

[4] Peter Menzies and Philip Pettit, 'In Defence of Fictionalism about Possible Worlds', Analysis 54 (1994) 27-36.

[5] Gideon Rosen, 'Modal Fictionalism', Mind 99 (1990) 327-54.

[6] Gideon Rosen, 'A Problem for Fictionalism about Possible Worlds', Analysis 53 (1993) 71-81. 